\title{
Enhancing the Quality of Humanitarian Assistance: Taking Stock and Future Initiatives
}

\author{
Andre Griekspoor, MD, MPH; ${ }^{1}$ Egbert Sondorp, $\mathrm{MD}, \mathrm{MPH}^{\mathbf{2}}$
}

\author{
1.Technical Officer, Department of \\ Emergency and Humanitarian Action, \\ World Health Organisation, Geneva, \\ Switzerland \\ 2. Senior Lecturer Public Health and \\ Humanitarian Aid, Health Policy Unit, \\ London School of Hygiene and Tropical \\ Medicine, London, United Kingdom \\ Correspondence: \\ Andre Griekspoor \\ Emergency Health Intelligence and \\ Capacity Building Officer \\ Department of Emergency and \\ Humanitarian Action \\ World Health Organisation \\ 20, Avenue Appia \\ $\mathrm{CH}-1211$ Geneva 27 \\ Switzerland
}

Keywords: accountability; ALNAP; assessment; benefits; complex emergencies; disaster; donors; evaluations; framework; governments; guidelines; humanitarian assistance; humanitarian organizations; international law; management; media; performance; projects; quality; regulation; Sphere Project

\footnotetext{
Abbreviations:

ALNAP = Active Learning Network

on Accountability and Preformance

$\mathrm{NGO}=$ non-governmental agency

OECD $=$ Organization for Economic

Cooperation and Development

UN = United Nations
}

\begin{abstract}
During the last five years, the debate on the performance of humanitarian assistance has intensified. The motivation to "do better" has come both from within the humanitarian agencies as well as from pressure exerted by the donors and the media. Paradoxically, until now, the voice of those who are to benefit from this assistance has not been heard.

This paper is an overview of the most important initiatives to increase the quality of humanitarian assistance. The introduction of the logical framework and the increasing body of knowledge made available through guidelines have improved project management by measuring process and outcomes. Increasingly, evaluations are used to give account and to learn from experiences. But, current evaluation practice must develop in a wider variety of approaches more appropriate to create change of the operations in the field. Some agencies oppose new developments like the Sphere and the Humanitarian Accountability Projects, arguing that standards and regulation would undermine necessary flexibility to adjust responses to the local context, or be a threat to their independence. Nonetheless, standards are considered to be a prerequisite as reference to assess performance. Furthermore, it is hoped that a new breakthrough will be achieved by improved accountability towards beneficiaries.

An option to address some of the gaps in the current quality assessment tools was to widen the perspective on performance from projects to the organisations behind them. Quality management models may provide the required framework, and they also can be used to embed current initiatives by organisations. Humanitarian organisations may want to develop forms of self-regulation rather than waiting for accreditation by donors. Another area in which progress is needed is a system-wide approach to performance. At this level, the influence of political actors, donors, national governments, and other representatives of the parties in a conflict also should be assessed. It is their legal obligation to protect the basic right to assistance of persons affected by disasters, as enshrined in international law.
\end{abstract}

Griekspoor A, Sondorp E: Enhancing the quality of humanitarian assistance: Taking stock and future initiatives. Prebosp Disast Med 2001:16(4):209-215.

\begin{abstract}
Introduction
In recent years, the debate on the performance of humanitarian assistance has intensified in response to a number of developments in the humanitarian system. During the 1980 s and early 1990 s, more and more implementing organisations
\end{abstract}

were established, more funds from donors and the general public became available, and the media paid increased attention to major human crises in the world. Thanks to growing organisational and logistical capacities, many agencies managed to 
negotiate access to people caught in conflict. The agencies were confronted with horrendous suffering, excess mortality, ${ }^{1}$ and flagrant abuses of human rights. However, by gaining access and the application of relatively simple measures, in particular in the fields of nutrition, water supply, and health care, at least some good could be accomplished. This further energised the agencies to build capacity to do even more. At the time, the general perception by the public towards humanitarian work was one of "always doing good."

However, the growth of the system itself, the very prolonged nature of many of contemporary conflicts, and most of all, the Rwanda crisis in 1994, gradually undermined the relative optimism that the humanitarian system was just "doing good". The realisation that many of these chronic conflicts were perpetuated by economic interests of the warring factions led to the notion that humanitarian aid, in fact, may fuel the conflict. ${ }^{2}$ Never before has the typical humanitarian dilemma of assisting genuine victims, while accepting some diversion to those in control, reached such an intensity as in the aftermath of the genocide in Rwanda.

Non-governmental organizations (NGOs) increasingly recognised their limitations to improve the lives in the affected populations provided only by delivering services. Depending upon their analysis of the key "root cause" of conflicts, various agencies began to combine service delivery with other activities. Some focused on advocacy work in the international arena, others on development and poverty reduction, and still others on a variety of peacebuilding initiatives.

Concurrently, a major evaluation of the emergency assistance to the Rwanda crisis came with serious concerns about the actual quality of service delivery by the humanitarian system. ${ }^{3}$ The report stated that 100,000 avoidable deaths could be attributed to poor performance on the part of the relief agencies. It concluded that the prevailing lack of standards and weak systems of accountability were, in no small part, responsible for many of these deaths.

Budgets allocated to humanitarian assistance by the Organization for Economic Cooperation and Development (OECD) reached an all time high of [U.S.] \$3.5 billion in 1994, a tenfold increase compared to $1980 .{ }^{4}$ Donor governments increase the amount in their budgets allocated to humanitarian assistance, partly out of response to obvious humanitarian needs, and partly out of a growing recognition that humanitarian assistance could be used as a political tool. ${ }^{5}$ Their increased interest was another drive to pay more attention to quality, impact, and accountability of humanitarian assistance. Considering humanitarian agencies as implementation channels, donors demanded value for money and evidence-based interventions.

This complex of internal and external pressures, and technical and political factors led to demands for better performance and increased accountability of humanitarian responses. ${ }^{6}$ Several new initiatives have emerged in recent years. Some humanitarian actors want to move towards standardisation and regulation; whereas, other agencies place priority upon the aspect of learning, retaining flexibility, and innovative approaches. This paper aims to highlight a number of the recent initiatives. It outlines some of their inherent limitations and obstacles to their implementation. Some areas inadequately addressed are explored, and it suggests what might be expected in the years to come.

\section{Overview \\ Developments to Improve the Quality of Humanitarian Assistance}

In the 1990s, most developments to improve humanitarian assistance have been based on the hard lessons learned during the Cold War conflicts. In the health sector, interventions mainly were curative and lacked norms and guidelines. People often worked in isolation. From the early 1990s, health agencies began to use more systematic epidemiological concepts to guide their interventions. ${ }^{7}$ The relevance of data collection and surveillance systems became more and more accepted. As organisations became larger, internal training programs and guidelines were developed. Humanitarian assistance started to become a specialised field with its own indicators, policies, and reference materials. 8,9 During the past five years, there has been a significant increase in numbers and quality of training courses and of Master's Degree programs related to humanitarian assistance and disaster management. ${ }^{10}$

\section{Code of Conduct}

The first voluntary Code of Conduct was developed by the Red Cross movement and non-governmental organizations (NGOs) in $1994 .{ }^{11}$ It seeks to safeguard high standards of behaviour, and to maintain the independence and effectiveness of disaster relief. In 10 principles, the Code promotes the impartial character of aid, the respect of local cultures, building on local capacities, and involvement of beneficiaries and respect for their dignity. Furthermore, it describes the relationships that humanitarian agencies should seek with donor governments, host governments, and the United Nations (UN) system.

\section{Logical Framework}

The logical framework planning method received increasing attention as a project management tool. Since it uses measurable indicators to quantify and qualify results, it seemed an ideal basis on which to document what agencies intended to do, and to verify whether or not they achieved their objectives. ${ }^{12}$ Many NGOs and donors have institutionalised this approach for planning, monitoring, reporting, and evaluation. ${ }^{13}$

The discussions on using evaluations to improve performance have gained momentum since 1996. Following the publication of the Joint Rwanda Evaluation, the first good practice review for evaluating humanitarian assistance was published in $1998 .{ }^{14}$ It consolidated ideas on how to assess performance, and on how to use evaluations for accountability and learning purposes. The evaluation criteria for coverage, connectedness, coherence, and appropriateness were added to relevance, effectiveness, efficiency, impact, and sustainability, as used in development assistance. After its adoption by the OECD, it became the dominant evaluation model for humanitarian assistance. ${ }^{15}$

In 1997, the Active Learning Network on Accountability 
and Performance (ALNAP) was established as a forum to promote learning in the humanitarian sector. Its members are drawn from the four pillars of the international humanitarian system: 1) bilateral donors, 2) the United Nations, 3) the Red Cross movement, and 4) the NGOs. ${ }^{16}$ It is a unique forum in which a wide variety of topics have been taken forward. Among others, the network maintains a database of evaluation reports and related publications, and it initiates studies, e.g., on accountability or the participation of beneficiaries.

Taking the criticism of the Rwanda evaluation seriously, the international humanitarian NGO community came together in a consortium called the Sphere Project. During three years, $>700$ people from 228 relief organisations in 60 countries consolidated ideas on good practice in a handbook published in January 2000.17 The Sphere Handbook contains a humanitarian charter and minimum standards accompanied by key indicators for five sectors of disaster response: water supply and sanitation, nutrition, food aid, shelter and site management, and health services. The Humanitarian Charter highlights the legal responsibility of states to guarantee the basic right to assistance of persons affected by disasters. Through worldwide dissemination, training programs, and workshops, Sphere aims to make a major contribution to improve performance by measuring process and outcome indicators.

Acknowledging the crucial role that aid workers play in providing assistance, the People in Aid Code of Best Practice was published in February $1997 .{ }^{18}$ The Code provides a framework to better support field staff. Agencies can sign up to use the Code, but also can use social and ethical accounting, auditing and reporting principles to report on how well their organisation performs against Code indicators.

In response to concerns about the lack of accountability towards the affected populations in crisis situations, the Humanitarian Ombudsman project started in 1997. This was changed into the Humanitarian Accountability project in $2000 . .^{19,20}$ It seeks to mobilise mechanisms of accountability at field, organisational, and sector-wide levels, based on the effective participation of affected populations and an ethical commitment to listen, monitor, and respond to their concerns.

Finally, the recognition that aid not only may be used to strengthen more positive forces, but potentially also may fuel local conflict, led to a framework developed by the Local Capacity for Peace Project. ${ }^{21}$ This framework, widely promoted and known as the "Do No Harm" principles, allows agencies to analyse how their activities may positively or negatively influence conflict resolution.

\section{Obstacles to Improving Performance}

Do all of the developments in the field of accountability and performance actually improve overall performance? This is very difficult to assess. We currently do not know how widely and how well the available tools are applied in the field, and system-wide evaluations, as was done after the Rwanda crisis, have been rare. In general, the initiatives are welcomed, and it may be too early to fully assess their impact. However, a number of observations can be made with regards to obstacles in the implementation of some of the initiatives mentioned, or to some of their inherent limitations. Furthermore, we will indicate some gaps where still new tools may need to be developed.

An enormous obstacle is the very nature of complex emergencies. Insecurity, evacuations, restricted access to affected populations, limited resources, and/or rapidly changing circumstances will place serious external constraints on anyone's intervention. Secondly, coordination so often is mentioned as a prerequisite for improved performance, but there is little interorganisational trust in the humanitarian system. The term "humanitarian complex" was used to emphasise that "the actors and institutions that collectively undertake humanitarian action do not form a coherent and integrated system with shared principles, policies, and modus operandi. 22 This always will be a hindrance to proper coordination. It is not just a matter of good will to ensure coordination: Aid agencies are too aware of the possibilities to be manipulated by donors, UN agencies, local governments, or rebel leaders.

A related problem is that some NGOs strongly resist the standardisation principles as promoted by the Sphere Project. ${ }^{23}$ The standards, in particular, the key indicators for most of the technical responses, are derived largely from work in refugee camps and similar acute emergencies. They can not always be used as planning objectives by NGOs working in more chronic or complex emergencies. Too strict adherence even may prevent relief workers from making necessary adjustments in complex situations. ${ }^{24} \mathrm{It}$ also is feared that an over-technical focus could increase the scope for political manipulation of humanitarian interventions or obscure responsibilities of political actors to address underlying causes of emergencies. Another concern is that the Sphere indicators could foster unrealistic expectations whilst ignoring constraints. Unjustified adverse publicity could have detrimental effects on public donations. We should keep in mind that operational standards apply to predictable situations with predictable problems and consensus on what to do. Complex situations require innovative responses. Here, one only can use simple rules: keep abreast of developments in your field, adapt these to the situation, and do no harm..$^{25}$

Despite the efforts of the Ombudsman project, the beneficiaries of humanitarian aid are not yet involved routinely in project design. Reasons include difficulties of identifying the right spokespersons or putting people at risk when they do participate. An additional reason could be the fear that what people ask for may not be within the organisation's ability to supply. Some agencies objected to the potential role of the Ombudsman as a policing mechanism for the Sphere standards and/or Code of Conduct. ${ }^{26}$ The agencies that are most vocal in their criticism of Sphere and the Ombudsman project were criticised for not coming up with alternatives. In response, these agencies initiated the Quality Project. ${ }^{27}$ This project wants to have a more holistic approach to quality, placing interventions in a wider political context, and in relation to external constraints and other humanitarian actors. It is based upon responsibilities towards affected populations, responsibilities towards other actors in the field, on technical and ethical guidance, the 
relation with donors, and on a process in which these are analysed.

The logical framework has a number of inherent shortcomings; for example, not taking into sufficient account the context in which programs take place, ${ }^{28}$ and that the existing framework does not do justice to the values of humanitarian assistance not covered by measurable indicators. Field staff often argue that the rapidly changing conditions during emergencies call for flexibility in planning and implementation, which the logical framework does not always include.

Evaluations are done when responses are coming to an end, and results usually are published long after the events took place. Classical evaluations using external evaluators seem to have the most added value for accountability and policy analysis, but not for direct operational improvements. There is concern that external evaluators do not sufficiently understand the external limiting conditions in complex emergencies or the organisation's specific mandate. Follow-up to evaluation recommendations often is limited, and is acknowledged to need improvement. ${ }^{29}$ Even though we may expect evaluations to yield important lessons, their inherent shortcomings mean that evaluations will not be able to meet the usually high expectations. A recent "state of the art" colloquium identified aspects of humanitarian assistance that had not been covered adequately: 1) protection, 2) coordination, 3) human resource issues, 4) context analysis, 5) knowledge management, 6) use of standards, 7) leadership, 8) costs, resource allocation, 9) advocacy, 10) impact on local society, and 11) satisfaction of the affected population. ${ }^{30}$

Furthermore, a number of areas can be identified for which no appropriate tools or mechanisms have been developed. There is no mechanism in the humanitarian system to assure or improve quality during the response. There still is no form of self-regulation to ensure quality of organisations despite recommendations of six years ago. ${ }^{3}$ There exists no mechanism for addressing system or sectorwide performance. Coordination often is limited to sharing information, but there is no systematic joint planning based upon situation and multi-sectoral needs analysis. There is no official accreditation system for humanitarian workers who often are entrusted with considerable budgets and far-reaching responsibilities. And last but not least, the role of the donors is not routinely taken into consideration. Questions regarding the optimal allocation of emergency funding between different sectors, let alone between different countries, have not been answered in any rational manner.

\section{Future Initiatives}

What can we expect to happen regarding quality enhancement in the next couple of years? In the health sector, technical knowledge, by and large, is available. ${ }^{31}$ It is much more a matter of getting the right knowledge to the right person at the right time, or, to be more precise, making technical knowledge available in a form that can be used by practitioners who are working under pressure and in adverse conditions. Innovative, interactive, web-based support mechanisms may be of help, but will need investment in its development and maintenance.
Proper project cycle management, including the use of a logical framework increasingly may be used by agencies, making their work more transparent and easier to monitor. This will take the will of agencies to go through the initial additional burden to introduce these tools in their organisation, which will include adequate staff training.

One may expect increased use of the standards, as promoted by Sphere, in planning, monitoring, and evaluation of emergency programs. The Sphere Handbook will go through an intensive revision during the next two years, and it is hoped that during this process, it will be able to address the criticism on its shortcomings. Mechanisms whereby agencies are held accountable with reference to minimal standards likely will be introduced. ${ }^{32}$ In particular, the development of good practice guidance on participation of beneficiaries in the planning, monitoring, and evaluation of disaster response is promising. ${ }^{33}$

Evaluations of humanitarian assistance have become increasingly popular. There still is a need to have more people in the health sector become familiar with the specific expertise of doing evaluations in a humanitarian context. Despite their inherent limitations, evaluations will remain a valuable tool. Their usefulness may be enhanced further if results routinely are made public, not for transparency reasons alone, but also to allow meta-analysis. ${ }^{34}$ There are recommendations to develop other approaches to evaluations that are more appropriate for learning and improving performance in the field. ${ }^{35}$ These include more use of selfevaluations, for example, through "lessons learned" workshops with teams and other stakeholders, and the newly developed concept of "real time evaluations" and the learning office. ${ }^{36} \mathrm{It}$ is interesting to note that some of these insights already were available in 1979, but apparently never were implemented. ${ }^{37}$

Evaluation of a single agency inevitably will show limitations, since the value of its activities are, to a large extent, dependent upon the overall level of achievement of the "humanitarian system". Nevertheless, good quality of the system starts with good quality of the individual components. When an NGO delivers services to a vulnerable population, they accept the duty to provide the best possible care given the resources it has at its disposal and within the constraints of the context in which they work. Or, to go one step further, a NGO would need to be as good as what another NGO could have done if they would have been given that same amount of resources. For the larger organisations, management becomes more important to remain effective and still allow for innovation. Donors interested to move from project funding to organisational funding, start to think about accreditation and regulation of humanitarian organisations. These lines of reasoning would require transparent and even standardised process approaches within the humanitarian organisations.

Quality management models may provide solutions to assess the quality of an organisation. In the United Kingdom, volunteer agencies formed the Quality Standards Task Group ${ }^{38}$ using the Excellence Model developed by the European Foundation for Quality Management. This model allows organisations to evaluate themselves or to be evaluated within their own mandate. It 


1. Leadership
2. Policy/strategy
3. Resource management
Human resources/people
Financial resources and means
Information and knowledge
4. Partnerships
Links with direct partners in service delivery
To coordinate within a sector
To coordinate intersectoral
5. Process
Primary process
Supportive process
Management process
6. Satisfaction of affected population
7. Satisfaction of human resources/people
8. Impact on soclety
Home society of the organisation
Local society where programs are implemented
9. Performance results
Protection
Operational
Financial

Prehospital and Disaster Medicine $\odot 2001$ Griekspoor
Table 1-Nine criteria to assess organisational quality (adapted from EFQM model)

- Ensure context-wide public health assessments, monitoring, and surveillance

- Identify gaps in information and undertake steps to collect additional data

- Assist analysing the health situation in the broadest sense as it evolves

- Identify needs for information on the human rights context and analysis of political economy of war

- Ensure coherent response, by translating the analysis in a health policy and health sector strategy, together with all relevant actors

- Provide input of good practise guidelines and minimum standards and/or help adjust these to the specific circumstances of that emergency

- Advise on appropriate and effective actions, assuring adequate coverage and equity

- Provide or facilitate training

- Identify needs for external experts

- Document experiences and identify opportunities for developing good practice guidance

- Organize "lessons learned" meetings and provide health sector accountability

Prehospital and Disaster Medicine@ 2001 Griekspoo

Table 2-Potential roles for a health sector "continuous quality improvement" group

has potential to institutionalise available tools, like the logical framework, evaluation, codes of conduct, and operational standards in the organisation. ${ }^{39}$ Using the model would put the obligation to involve beneficiaries, and to ask for their satisfaction with services received, high on the agenda of organisations. It can provide recognition for improvements made in quality management. ${ }^{40}$ The nine aspects of an organisation described by this model address some of the topics raised in the New York colloquium as gaps in the current evaluation criteria (Table 1). ${ }^{30}$

Since the joint Rwanda evaluation, no other similar initiatives have been undertaken. It is time to open the debate on methods and mechanisms to assess the system-wide response to emergencies. This would require a better understanding on measures of effectiveness of humanitarian assistance at large. Survival, health, human rights, and the dignity of the affected populations can be used as crosscutting objectives. But, such an analysis also should assess if the response has been able to address the underlying factors and determinants that led to the crisis: the environment, water and food security, as well as the political, social, cultural, and economic factors. Although it may not be possible to attribute achievements to single agencies, the contributions of the various actors, national and international, can be analysed against their mandates. This would include looking at the roles of institutional donors, national governments, and leaders of other parties to a conflict.

Mechanisms are needed in a single emergency context to get the relevant partners together and find ways to put these ideas into practise. One option would be to strengthen interagency processes like the Common Humanitarian Action Plan and the Consolidated Appeal Process. ${ }^{41}$ Although mainly perceived as a fund-raising tool, there now is more recognition that it should be used as a strategic planning and monitoring tool within and between sectors. We believe that the improved setting of policy and strategy and a systematic process to set program priorities and develop optimal modes of implementation for the health sector at large, fully adapted to the current situation, may provide more guidance to individual agencies taking up the implementation of part of this policy. The WHO currently is promoting a number of studies to assess how such policy and strategy setting in complex emergencies can be put into practice. ${ }^{42}$

Another innovative approach would be to find ways to infuse evaluative processes and learning functions during the implementation of emergency responses. Within ALNAP, the concept of the Learning Office has been developed to do this at the system level. ${ }^{36} \mathrm{Within}$ the health sector, a precursor for such a function was the epidemiology group established in 1994 during the Goma crisis. $^{43}$ Building further on these experiences, the scope could be expanded beyond epidemiological surveillance and epidemic control. It should have a public health perspective and be able to advise program priorities not restricted to the area of operation of any single agency (Table 2). ${ }^{44}$ To ensure optimal implementation, the Learning Office concept should facilitate and mobilize expertise available on the ground.

\section{Conclusions}

Recent initiatives focusing on enhancing the quality in the humanitarian system have been discussed, with some of their limitations. Overall, they present a wide scope of instruments to assess performance. We identified the need to develop new tools to assess performance of humanitarian organisations. Furthermore, we believe that it is necessary 
to promote evaluative processes at sector and system-wide levels. It is hoped that a new breakthrough will be achieved by improved accountability towards beneficiaries.

Lessons can be learned from what other comparable sectors did to overcome similar problems. Quality assurance and quality management principles probably will find their way into the humanitarian system. Some may greet this with skepticism and concern, similar to the apprehension regarding the logical framework and minimum standards. Rather than waiting until donors impose external accreditation systems on humanitarian organisations, it seems preferable for the NGOs to opt for self-regulation.

Performance of humanitarian agencies should be assessed in relation to their mandates and in relation to their responsibilities towards their various stakeholders. Nevertheless, an inherent and virtually insurmountable problem in comparing agency performance is the different strategies that agencies choose to address humanitarian problems. Such difference in strategy is an expression of the agencies' chosen mandate, its corporate culture and capacity, and their view on the root cause of the problem and the solutions thereof. All would provide some form of direct service. Some, however, would seek to maximise the direct impact using public health approaches and costeffectiveness considerations. For others, solidarity and protection through proximity is a primary goal. Others would want to link their humanitarian assistance with "development" or "peace-building" or, at least, act in a way to "do no harm" whereas some couple their assistance with advocacy activities at the international stage. In addition, most agencies, one way or the other, will be influenced by donor choices, linking humanitarian assistance to political goals and conditional ties.

Humanitarian assistance not only should be sound technically, but also the approach of its implementation is important to avoid unanticipated negative side effects, and to foster medium- and long-term solutions. Researchers only just are beginning to understand and describe all of these different approaches and influences, ${ }^{45}$ and we still are a long way from applying these to more practical assessments of performance in the field.

\section{References}

1. Reed H, Keely CB: Forced Migration and Mortality. Roundtable on the demography of forced migration committee on population. National Academy Press: Washington DC, 2001.

2. Duffield M: The Political Economy of Internal War: Asset Transfer, Complex Emergencies and International Aid. In: Macrae J, Zwi A [eds], War and Hunger, 1994. pp 50-69.

3. Overseas Development Institute (ODI): Joint Evaluation of Emergency Assistance to Rwanda, Study III: Humanitarian Aid and Effects. ODI: London, UK. 1995.

4. Development Assistance Committee on International Development Statistics: The Total Net Flow of Financial Resources from DAC Countries to Developing Countries and Multilateral Organisations by Type of Flow, Table 2. http://www.oecd.org/dac/htm/dacstats.htm Accessed 27 August 2001.

5. Macrae J, Leader N: The Politics of Coherence: Humanitarianism and Foreign Policy in the Post-Cold War Era. Overseas Development Institute: London. 2000.

6. Overseas Development Institute (ODI): The State of the International Humanitarian System. Briefing paper. Overseas Development Institute: London, March 1998 (1).

7. Hakewill PA, Moren A: Monitoring and evaluation of relief programs. Tropical Doctor 1991;Supplement 1:24-28.

8. Médecins Sans Frontières: Refugee Healtb; An Approach to Emergency Situations. Macmillan: London. 1997.

9. Noji EK, Toole MJ: The historical development of public health response to disasters. Disasters 1997;21(4):366-376.

10. Interaction: Programs and courses for disaster response professionals. An inventory prepared by Interaction. http://www.multidb.com/interactiontraining/. Accessed 01 September 2001.

11. Code of Conduct for the International Red Cross and Red Crescent movement and NGOs in disaster relief. Geneva, 1994. http:/www.ifrc.org/publicat/conduct/. Accessed 27 August 2001.

12. Commission of the European Communities Evaluation Unit: Manual Project Cycle Management. Integrated approach and Logical Framework. Methods and Instruments for Project Cycle Management. No.1, February 1993.
13. Borton J: Progress Report on the ALNAP Small Study: Achieving Greater Commonality in the Monitoring and Reporting of Humanitarian Assistance. ALNAP, ODI: London. 1998.

14. Hallam A: Good Practice Review 7, In: Evaluating Humanitarian Assistance Programs in Complex Emergencies. Relief and Rehabilitation Network. Overseas Development Institute: London. September 1998.

15. OECD/DAC: Guidance for evaluating humanitarian assistance in complex emergencies. 1999. http://www.oecd.org/dac/htm/pubs/p_eval.htm. Accessed 28 August 2001.

16. The Active Learning Network for Accountability and Performance in Humanitarian Action. www.odi.org.uk/alnap. Accessed 28 August 2001.

17. The Sphere Project: Humanitarian Charter and Minimum Standards in Disaster Response, 1st ed. Geneva 2000. http://www.sphereproject.org.

18. People in Aid: Promoting best practice in the management and support of aid personnel. http://www.peopleinaid.org/. Accessed 27 August 2001.

19. Ombudsman Project: Outcome and Next Steps. Humanitarian Ombudsman Project Meeting. Geneva, 16 March 2000.

20. Humanitarian Accountability Project. http://www.hapgeneva.org. Accessed 27 August 2001

21. Anderson MB: Do No Harm: How Aid Can Support Peace-Or War? Revised 1999 Local Capacity for Peace Project www.cdainc.com/lcpp-index.htm. Accessed 30 May 2001.

22. Stockton $N$ (speaking notes): Keeping the International Community Involved in Zones of Conflict No Longer in Fashion. Taplow Court, 04 March 2000.

23. Gostelow L: The Sphere Project: The implications of making humanitarian principles and codes work. Disasters 1999;23:4.

24. Griekspoor A, Collins S: Raising standards in emergency relief: A debate on the usefulness of the "Sphere" minimum standards for humanitarian assistance. Accepted for publication, BMJ 18 June 2001,

25. Personal communication: Marius Buiting, $\mathrm{CBO}$, Instinte for Quality in Utrecht, The Netherlands.

26. Platforme des ONG pour une autre approche qualité de l'action humanitaire Groupe URD: May 2000. http:/www.urd.org/rech/sphere/platform.htm. Accessed 27 August 2001. 
27. Projet qualite projet pour l'amelioration de la qualite de l'action humanitaire. Groupe URD: July 2000. http://www.urd.org/projqual/1 prqual.htm. Accessed 27 August 2001.

28. Gaspers D: Logical Frameworks: A critical assessment. Working paper no.278. Institute of Social Sciences: The Hague: The Netherlands. 1997.

29. Van de Putte B: Follow-up to evaluations of humanitarian programs. Findings of the ALNAP commissioned study: Improving the Follow-up to Evaluations of Humanitarian Programs. April 2001.

30. ALNAP: Report on the ALNAP 'State of the Art' Colloquium on Humanitarian Evaluation. UNICEF House: New York, 02-03 October, 2000.

31. World Health Organization and the Pan-American Health Organization in collaboration with the ICRC, UNHCR, UNICEF, and the Sphere Project. The global virtual library of essential information resources of public health for disasters and complex emergencies. Health Library for Disasters on $C D-$ ROM, www.who.int/eha/disasters/.

32. Salama P, Buzard N, Spiegel P: Improving standards in international humanitarian response: The Sphere Project and Beyond. JAMA 2001;286:5: 531-532.

33. ALNAP: Global study to improve consultation with, and participation by, beneficiaries and affected populations in the process of planning, managing, monitoring and evaluating humanitarian programs. Planned study. 2001.

34. Houghton R, Robertson K: ALNAP Annual review 2001: Humanitarian Action: Learning from Evaluation. ODI: London. 2001.

35. Van de Putte B: Synthesis study of the first 10 evaluations done through the M\&E unit. Medecins Sans Fronticres: Amsterdam. May 2000.
36. Reddick M, Telford J: Further Development of the Learning Office Concept with Reference to Sierra Leone and East Timor and a Developed Proposal to Run a Test Office during 2001, October 2000. http://www.alnap.org/ alnappubs.html. Accessed 10 September-2001.

37. Taylor AJ, Cuny FC: The evaluation of humanitarian assistance. Conference report. Disasters 1979;3(1):37-42.

38. NCVO: Quality for the voluntary sector. http://www.ncvo-vol.org. uk/main/about/does/qs.html. Accessed 29 August 2001.

39. Griekspoor A: From doing good to doing good things right: An analysis on the applicability of the EFQM model for Quality Management to Humanitarian Organisations. Final paper, MPH, Netherlands School of Public Health, Utrecht. 02 June, 2000.

40. Nabitz U, Klazinga NS: EFQM approach and the Dutch Quality Award. International Journal of Health Care Quality Assurance 1999;12(2):65-70.

41. United Nations Office for the Coordination of Humanitarian Assistance. Technical Guidelines for the Consolidated Inter-Agency Appeals Process. Updated draft, August 2001.

42. WHO: 2000: Proposal for a Series of Studies on Public Health and Humanitarian Action. http://www.who.int/disasters/tg.cfm?doctypeID=17.

43. Goma Epidemiology Group. Public health impact of Rwandan refugee crisis: What happened in Goma, Zaire, in July 1994? Lancet 1995;345: 339-344.

44. Waldman R: Prioritising health care in complex emergencics. Lancet 2001;357:1427-1429.

45. Curtis D: Politics and Humanitarian Aid: Debates, Dilemmas and Dissension. Overseas Development Institute: London. 2001. 